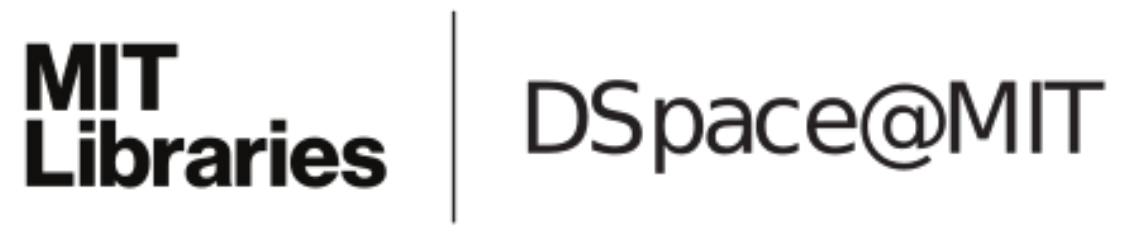

\author{
MIT Open Access Articles
}

When is it good to believe bad things?

The MIT Faculty has made this article openly available. Please share how this access benefits you. Your story matters.

Citation: Ackerman, Joshua M., Jenessa R. Shapiro, and Jon K. Maner. "When Is It Good to Believe Bad Things?" Behavioral and Brain Sciences 32.06 (2010) : 510.

As Published: http://dx.doi.org/10.1017/s0140525x09991142

Publisher: Cambridge University Press

Persistent URL: http://hdl.handle.net/1721.1/65926

Version: Author's final manuscript: final author's manuscript post peer review, without publisher's formatting or copy editing

Terms of use: Creative Commons Attribution-Noncommercial-Share Alike 3.0 
Commentary on McKay \& Dennett

Abstract: 56 words

Main text: 988 words

References: 724 words

Total text: 1768 words

\section{When is it good to believe bad things?}

Joshua M. Ackerman

Sloan School of Management

Massachusetts Institute of Technology

1 Amherst St., E40

Cambridge, MA 02142

USA

Tel: 617-258-9102

joshack@mit.edu

http://web.mit.edu/joshack/www/

Jenessa R. Shapiro

Department of Psychology

University of California, Los Angeles

Box 951563

Los Angeles, CA 90095-1563

USA

jshapiro@psych.ucla.edu

Jon K. Maner

Department of Psychology

Florida State University

1107 W. Call Street

Tallahassee, FL 32306-4301

USA

maner@psy.fsu.edu

http://www.psy.fsu.edu/faculty/maner.dp.html

\section{Abstract:}

Positive and negative misbeliefs both may have evolved to serve important adaptive functions. Here, we focus on the role of negative misbeliefs in promoting adaptive outcomes within the contexts of romantic relationships and intergroup interactions. Believing bad things can paradoxically encourage romantic fidelity, personal safety, competitive success and group solidarity, as well as other positive outcomes. 
In their article, McKay and Dennett define evolved misbeliefs, or illusions, as those that are adaptively superior to fully accurate beliefs. The authors focus their discussion on the value of positive misbeliefs, but there are also reasons to believe that negative misbeliefs can serve adaptive functions as well. Below, we consider negative misbeliefs within two important social contexts: (1) close relationships and (2) intergroup interactions.

\section{Misbeliefs related to close relationships}

The formation and maintenance of close relationships are fundamental human pursuits (Ackerman \& Kenrick, 2008; Kenrick, Griskevicius, Neuberg, \& Schaller, in press). Romantic relationships are particularly important because mating represents the sine qua non of evolutionary success. Positive misbeliefs may aid these romantic pursuits, as in McKay and Dennett's example of the over-perception of positive spousal attributes. However, close relationships may also benefit from negative illusions. For instance, women tend to believe that men are less interested in romantic commitment than those men actually are (Haselton \& Buss, 2000), especially prior to the onset of sexual activity in relationships (Ackerman, Griskevicius, \& Li, 2009). McKay and Dennett suggest that, although the system that generates such misbeliefs is probably adaptive, misbeliefs themselves are not (because accurate beliefs would be equally protective without suffering from false positive errors). However, underestimating male commitment could lead women to set higher thresholds for suitors to overcome, leading men to expend greater effort and investment (see Ackerman \& Kenrick, in press), and ultimately boosting the romantic returns that women receive (e.g., mate quality, economic resources, actual commitment). Conversely, accurate beliefs about potential romantic partners might facilitate accurate decision making, but would be unlikely to garner these additional benefits.

Another example pertains to misbeliefs about alternative relationship partners. People in committed relationships tend to display cognitive biases that inhibit straying from those relationships (e.g., Maner, Gailliot, \& Miller, 2009; Maner, Rouby, \& Gonzaga, 2008), such as believing that attractive relationship alternatives are less appealing than they actually are (Johnson \& Rusbult, 1989; Simpson, Gangestad, \& Lerma, 1990). These negative illusions down-regulate threats posed by romantic alternatives, increasing the long-term success of one's current relationship. Long-term romantic relationships serve important functions linked to social affiliation and offspring care, as well as the more obvious reproductive benefits, and thus negative misbeliefs about relationship alternatives can promote a range of adaptive outcomes. Accurate beliefs about attractive alternatives, however, could promote infidelity and destabilize one's relationship.

\section{Misbeliefs related to intergroup interactions}

In addition to romantic relationships, group-level relationships are also fundamental components of human evolutionary success (Kenrick et al., in press; Neuberg \& Cottrell, 2006). Throughout human evolutionary history, hostile outgroups have posed threats to personal safety and group resources. Many of these threats were transient, with periods of conflict interspersed with periods of relative peace (e.g., Baer \& McEachron, 1982). 
Accurate beliefs acknowledging that outgroups were not always threatening could have supported increased intergroup contact. However, the potential for threat in intergroup interactions would likely remain high, as initially peaceful or cooperative encounters between unfamiliar parties can quickly turn dangerous (e.g., through simple misunderstandings or signals of vulnerability). Negative outgroup illusions could have enhanced fitness to the extent that they led people to be wary, reducing the probability of loss or harm from a hostile outgroup member (see Ackerman et al., 2009).

In fact, negative misbeliefs can strengthen the drive to compete with other groups for status and resources (Campbell, 1965; Sherif, Harvey, White, Hood, \& Sherif, 1961). For example, sports teams may perform better because of the misbeliefs they hold about the motivation and skill of their rivals. Similarly, religions may facilitate conversion by asserting the falsity and profaneness of other gods. In the political realm, nations are frequently in conflict with one another over natural and social resources, and exhibit extreme ideological and ethnocentric beliefs as a result (Campbell, 1965). Governments that construe other nations as "Evil Empires" may be more motivated to economically out-produce and even attack those nations (thereby attaining resources, if they win). In contrast, accurate beliefs about opposing groups would provide no extra incentive to compete and might even de-motivate groups with relatively lower standing and abilities.

Much of the work on negative misbeliefs and intergroup threat has explored the role of race as a heuristic cue to group membership. People tend to associate particular racial groups with specific threats (e.g., Black males with physical danger; Cottrell \& Neuberg, 2005), and these biases become especially strong in the presence of other threat-relevant cues (e.g., angry expressions). For example, people believe that neutrally expressive outgroup men are more threatening when seen in the context of other, angry outgroup men (Shapiro et al., in press); frightened people believe that outgroup men are more angry than they truly are (Maner et al., 2005); and pregnant women, whose fetuses are especially vulnerable early in development, exhibit greater ethnocentric beliefs during their first trimester (Navarrete, Fessler, \& Eng, 2007). Such negative illusions could promote outgroup avoidance (see also Mortensen et al., in press) which, in evolutionary contexts, could have served important self-protective functions.

Finally, misbeliefs about outgroup threat elicit not only outgroup avoidance, but also ingroup solidarity (Becker et al., 2009; Coser, 1956; Tajfel \& Turner, 1986). This solidarity provides a number of advantages. Consider that the pursuit of economic and physical resources is often a zero-sum game, and thus groups must manage their resources by discouraging exploitation from selfish members. Cooperation is one solution to potential intragroup conflict, and negative illusions about the dangers of other groups may improve cooperation by providing a common threat and promoting intragroup unity (e.g., Hammond \& Axelrod, 2006; Van Vugt, De Cremer, \& Janssen, 2007).

\section{Conclusion}

Many negative misbeliefs continue to provide adaptive benefits in modern times, and yet may also result in detrimental social outcomes such as the perpetration of problematic 
stereotypes and prejudices. Despite such modern troubles, there is reason to believe that, as with positive misbeliefs, negative misbeliefs evolved to meet recurrent challenges in the ancestral world. 


\section{References}

Ackerman, J. M, Becker, D. V., Mortensen, C. R., Sasaki, T., Neuberg, S. L, \& Kenrick, D. T. (2009). A pox on the mind: Disjunction of attention and memory in processing physical disfigurement. Journal of Experimental Social Psychology, $45,478-485$.

Ackerman, J. M., Griskevicius, V., \& Li, N. (2009). Let's get serious: Communicating commitment in romantic relationship formation. Manuscript submitted for publication.

Ackerman, J. M., \& Kenrick, D. T. (2008). The costs of benefits: Help-refusals highlight key trade-offs of social life. Personality and Social Psychology Review, 12, 118140.

Ackerman, J. M., \& Kenrick, D. T. (in press). Cooperative Courtship: Helping Friends Raise and Raze Relationship Barriers. Personality and Social Psychology Bulletin.

Ackerman, J. M., Shapiro, J. R., Neuberg, S. L., Kenrick, D. T., Becker, D. V., Griskevicius, V., et al. (2006). They all look the same to me (unless they're angry): From out-group homogeneity to out-group heterogeneity. Psychological Science, 17, 836-840.

Baer, D., \& McEachron, D. L. (1982). A review of selected sociobiological principles: Application to hominid evolution I: The development of group structure. Journal of Social \& Biological Structures, 5, 69-90.

Becker, D. V., Mortensen, C. R., Ackerman, J. M., Shapiro, J. R., Anderson, U. S., Sasaki, T., et al. (2009). Self-protection and revenge-mindedness modulate detection of enemy insignia. Manuscript submitted for publication.

Campbell, D. T. (1965). Ethnocentric and other altruistic motives. In D. Levine (Ed.), Nebraska Symposium on Motivation (pp. 283-311). Lincoln, NE: University of Nebraska Press.

Coser, L. A. (1956). The functions of social conflict. Glencoe, IL: Free Press.

Cottrell, C. A., \& Neuberg, S. L. (2005). Different emotional reactions to different groups: A sociofunctional threat-based approach to 'prejudice.' Journal of Personality and Social Psychology, 88, 770-789.

Hammond, R. A., \& Axelrod, R. (2006). The Evolution of Ethnocentrism. Journal of Conflict Resolution, 50, 926-936.

Haselton, M. G., \& Buss, D. M. (2000). Error management theory: A new perspective on biases in cross-sex mind reading. Journal of Personality and Social Psychology, 78, 81-91.

Johnson, D. J., \& Rusbult, C. E. (1989). Resisting temptation: Devaluation of alternative partners as a means of maintaining commitment in close relationships. Journal of Personality and Social Psychology, 57, 967-980.

Kenrick, D. T., Griskevicius, V., Neuberg, S. L., \& Schaller, M. (in press). Renovating the Pyramid of Needs: Contemporary Extensions Built Upon Ancient Foundations. Perspectives on Psychological Science.

Maner, J. K., Gailliot, M. T., \& Miller, S. L. (2009). The implicit cognition of relationship maintenance: Inattention to attractive alternatives. Journal of Experimental Social Psychology, 45, 174-179. 
Maner, J. K., Kenrick, D. T., Neuberg, S. L., Becker, D. V., Robertson, T., Hofer, B., et al. (2005). Functional projection: How fundamental social motives can bias interpersonal perception. Journal of Personality and Social Psychology, 88, 63-78.

Maner, J. K., Rouby, D. A., \& Gonzaga, G. (2008). Automatic Inattention to Attractive Alternatives: The Evolved Psychology of Relationship Maintenance. Evolution \& Human Behavior, 29, 343-349.

Mortensen, C. R., Becker, D. V., Ackerman, J. M., Neuberg, S. L., \& Kenrick, D. T. (in press). Infection breeds reticence: The effects of disease salience on selfperceptions of personality and behavioral avoidance tendencies. Psychological Science.

Navarrete, C. D., Fessler, D. M. T., \& Eng, S. J. (2007). Increased ethnocentrism in the first trimester of pregnancy. Evolution and Human Behavior, 28, 60-65.

Neuberg, S. L., \& Cottrell, C. A. (2006). Evolutionary Bases of Prejudices. In M. Schaller, J. A. Simpson, \& D. T. Kenrick (Eds.), Evolution and Social Psychology (pp. 163-187). New York: Psychology Press.

Shapiro, J. R., Ackerman, J. M., Neuberg, S. L., Maner, J. K., Becker, D. V., \& Kenrick, D. T. (in press). Following in the Wake of Anger: When not Discriminating is Discriminating. Personality and Social Psychology Bulletin.

Sherif, M., Harvey, O. J., White, B. J., Hood, W. R., \& Sherif, C. W. (1961). Intergroup conflict and cooperation: the Robbers Cave experiment. Norman: Institute of Group Relations, University of Oklahoma.

Simpson, J. A., Gangestad, S. W., \& Lerma, M. (1990). Perception of physical attractiveness: Mechanisms involved in the maintenance of romantic relationships. Journal of Personality and Social Psychology, 59, 1192-1201.

Tajfel, H., \& Turner, J. (1986). The social identity theory of intergroup behavior. In S. Worchel \& W. G. Austin (Eds.), Psychology of intergroup relations (pp. 7-24). Chicago: Nelson-Hall.

Van Vugt, M., De Cremer, D., \& Janssen, D. (2007). Gender differences in competition and cooperation: The male warrior hypothesis. Psychological Science, 18, 19-23. 